\title{
Avaliação da atividade antibacteriana de extratos etanólico e de ciclohexano a partir das flores de camomila (Matricaria chamomilla L.)
}

\author{
CARVALHO, A.F.1,2; SILVA, D.M.'; SILVA, T.R.C'; SCARCELLI, E.2; MANHANI, M.R. ${ }^{1}$ \\ ${ }^{1}$ Universidade São Judas Tadeu. R. Taquari, 546. CEP 03166-000, São Paulo, SP, Brasil. ${ }^{2}$ Instituto Biológico - \\ Centro de Pesquisa e Desenvolvimento de Sanidade Animal. Av. Cons. Rodrigues Alves 1252, CEP 04014-002, \\ São Paulo, SP, Brasil. *linebio@gmail.com
}

\begin{abstract}
RESUMO: Devido à crescente seleção de microrganismos resistentes aos antimicrobianos atuais, temse valorizado a busca por alternativas naturais. O presente estudo teve por objetivo avaliar a atividade antibacteriana de extratos etanólico e de ciclohexano de flores de camomila, espécie vegetal de uso antigo pela medicina tradicional, frente às bactérias ATCC Staphylococcus aureus, Pseudomonas aeruginosa, Escherichia colie Salmonella enterica subsp. enterica sorovar Typhimurium pelas técnicas de difusão em ágar e diluição em caldo. Foi observada inibição do crescimento de $P$. aeruginosa frente ao extrato etanólico bruto $(1 \mathrm{~g} / \mathrm{mL})$ na técnica de diluição em caldo, e confirmada pela técnica de difusão em ágar (halo de inibição de $10 \mathrm{~mm}$ de diâmetro). Para as demais bactérias testadas, os extratos e suas diluições não apresentaram efeito bacteriostático em nenhuma das técnicas. Podese concluir que o extrato etanólico bruto da camomila apresentou atividade antibacteriana frente à $P$. aeruginosa, porém não foi eficaz frente à $S$. aureus, $E$. coli e Salmonella enterica subsp. enterica sorovar Typhimurium. Portanto, são necessários novos estudos com diferentes linhagens de microrganismos, com o intuito de corroborar e assegurar os resultados apresentados, para definir o potencial antimicrobiano do extrato da camomila.
\end{abstract}

Palavras-chave: extrato de camomila, atividade biológica, Pseudomonas aeruginosa

\begin{abstract}
Evaluation of the antibacterial activity of ethanolic and cyclohexane extracts of chamomile flowers (Matricaria chamomilla L.). Due to the growing selection of microorganisms resistant to antimicrobial, the search for natural alternatives has become popular. The objective of the present study was to evaluate the antibacterial activity of ethanolic and cyclohexane extracts of chamomile flowers, a plant species long used by traditional medicine, against ATCC bacteria Staphylococcus aureus, Pseudomonas aeruginosa, Escherichia coli and Salmonella enterica subsp. enterica serovar Typhimurium by agar diffusion and broth dilution techniques. Growth of $P$. aeruginosa was inhibited when crude ethanolic extract $(1 \mathrm{~g} / \mathrm{mL})$ was used broth dilution, and was confirmed by agar diffusion, (10 $\mathrm{mm}$ diameter inhibition zone). For the other bacteria tested, the extracts and their dilutions did not show any bacteriostatic effect in any of the techniques. It may be concluded that pure ethanolic extract of chamomile presents antibacterial action against $P$. aeruginosa, and none against $S$. aureus, E. coli e Salmonella enterica subsp. enterica sorovar Typhimurium. However, other studies with different strains of microorganisms may be useful in order to corroborate and ensure these results, to define evaluation of the antimicrobial activity of chamomile extract.
\end{abstract}

Keywords: chamomile extract, biological activity, Pseudomonas aeruginosa

\section{INTRODUÇÃO}

A seleção de patógenos resistentes aos antimicrobianoséum dos casos mais bem documentados de evolução biológica, e um sério problema em países desenvolvidos e em desenvolvimento, desafiando a antibioticoterapia humana e animal (Duarte, 2006). Embora muitas indústrias farmacêuticas tenham produzidos novos antibióticos e modificado alguns fármacos já existentes, o consumo excessivo de antibacterianos em alguns países, tem resultado no aumento de resistência bacteriana, causando sério problema de saúde pública (Santos et al., 2007; Duarte, 2006).

Recebido para publicação em 23/11/2012 
Por outro lado, os medicamentos fitoterápicos estão sendo empregados como alternativas no tratamento contra diferentes patógenos. A partir dos extratos e óleos essenciais das plantas, são obtidos compostos que, apesar de conter estruturas químicas diferenciadas dos antimicrobianos produzidos a partir de bactérias e fungos, têm demonstrado eficiência no controle do crescimento de uma ampla variedade de microrganismos. Na sua maioria, os constituintes químicos responsáveis pela atividade farmacológica não são conhecidos, mas acredita-se que envolva a interação de inúmeras moléculas presentes no extrato (Yunes \& Calixto, 2001). Dados sobre a atividade antibacteriana de extratos vegetais frente a variados microrganismos permitem evidenciar que as plantas apresentam potencial para o tratamento terapêutico, apesar de muitos destes extratos não terem sido completamente investigados cientificamente (Nascimento et al., 2000).

Segundo a Organização Mundial de Saúde (OMS), as plantas medicinais são a melhor fonte para a obtenção de uma variedade de moléculas biologicamente ativas, e cerca de $80 \%$ da população mundial usa a medicina tradicional na busca de alívio de alguma sintomatologia dolorosa ou desagradável (Nascimento et al., 2000).

Quando se procura obter substâncias ativas de plantas, um dos principais aspectos a ser observado é a informação obtida da medicina popular. A Matricaria chamomilla L., conhecida popularmente como camomila, é uma das plantas de uso mais antigo pela medicina tradicional europeia, e hoje é incluída como oficial nas farmacopeias de quase todos os países. Apresenta princípios ativos como o óleo essencial alfa-bisabolol, que contém camazuleno e camaviolino, além de flavanóides, apigenina, taninos, matricina, cumarinas, polissacarídeos e éteres bicíclicos. É utilizada na medicina científica e na popular como tônico amargo, digestivo, sedativo e antiespasmódico, agindo também por via tópica pela aplicação de compressa quente sobre o abdômen no tratamento de cólicas. A infusão aquosa das flores ou o próprio óleo essencial são empregados em pomadas e cremes com poder antiinflamatório, cicatrizante, analgésico e antivirótico (Lorenzi \& Matos, 2002).

Existe um grande número de espécies vegetais no mundo que são consideradas medicinais e bastante utilizadas pela população, porém ainda são necessários mais estudos científicos sobre a atividade biológica dessas plantas para sua efetiva utilização. Portanto, o presente estudo teve por objetivo avaliar a atividade antibacteriana de extratos etanólico e de ciclohexano obtidos a partir das flores de Matricaria chamomilla L., visando à inibição de linhagens de Staphylococcus aureus, Pseudomonas aeruginosa, Escherichia coli e Salmonella enterica subsp. enterica sorovar Typhimurium, que são bactérias patogênicas ao homem e animais, e que vem apresentando um perfil amplamente disseminado de resistência aos antimicrobianos atuais, constituindo problemas terapêuticos difíceis de serem erradicados, valorizandose, assim, a procura por alternativas naturais.

\section{MATERIAL E MÉTODO}

Foram adquiridos capítulos florais no estado seco de Matricaria chamomilla L., família Asteraceae, de amostra comercial pronta para consumo, em supermercado do estado de São Paulo, Brasil, sendo a matéria prima e a indústria, brasileiras, de lote L51T02, fabricação em 19/08/2011 e validade de dois anos.

Foram realizadas extrações com dois solventes diferentes para obtenção dos extratos vegetais: uma extração a frio, utilizando-se o solvente polar álcool etílico $96^{\circ} \mathrm{GL}$ como líquido extrator, obtendo-se um extrato etanólico; e uma extração exaustiva a quente, utilizando-se o solvente apolar ciclohexano, obtendo-se um extrato de ciclohexano.

Em um béquer foram colocadas $100 \mathrm{~g}$ de flores secas de Matricaria chamomilla L. e álcool etílico $96^{\circ} \mathrm{GL}$ até cobrir o material vegetal por inteiro. Tampou-se o béquer com papel filme, e, após 72 horas em temperatura ambiente, realizou-se uma filtragem utilizando-se papel filtro estéril (Bayoub et al., 2010).

Para a extração a frio, segundo adaptação da metodologia descrita por Ribeiro (2008), utilizou-se o filtrado que foi levado ao evaporador rotatório para a eliminação do solvente e separação do extrato, por aproximadamente 4 horas a $50^{\circ} \mathrm{C}$. Obtido o extrato etanólico seco bruto, este foi ressuspendido em água destilada estéril, ajustando a concentração final para $1 \mathrm{~g}$ de extrato seco correspondente a $1 \mathrm{~mL}$ de água destilada. Do volume total de extrato concentrado obtido (aproximadamente $7 \mathrm{~mL}$ ) foram feitas diluições com água destilada estéril de 1:1, 1:2, 1:4, 1:8 e 1:10. As concentrações obtidas foram: 1000; 500; 250; 125; 62,5 e $31,25 \mathrm{mg} / \mathrm{mL}$; respectivamente.

Segundo adaptação da metodologia descrita por BRASIL (2010), com a camomila retida na filtração, foi realizada uma extração exaustiva a quente sob refluxo utilizando o extrator de Soxhlet, a aproximadamente $70^{\circ} \mathrm{C}$, por 2 horas e meia com o solvente ciclohexano. Após obtenção do extrato, este sofreu evaporação em chapa de aquecimento elétrica à aproximadamente $90^{\circ} \mathrm{C}$ em capela de exaustão, até a total eliminação do solvente. $\mathrm{O}$ extrato seco bruto obtido foi ressuspendido em água estéril contendo $10 \%$ de tensoativo monoláurico (Tween 20) para facilitar a dissolução, ajustando a concentração final para $1 \mathrm{~g}$ de extrato seco correspondente a $1 \mathrm{~mL}$ de solução. Do volume total do extrato concentrado obtido (aproximadamente 7,8 mL) foram feitas diluições com 
água destilada estéril de 1:1, 1:2, 1:4, 1:8 e 1:10. As concentrações obtidas foram: 1000; 500; 250; 125; 62,5 e $31,25 \mathrm{mg} / \mathrm{mL}$; respectivamente.

Para avaliação do efeito antibacteriano da Matricaria chamomilla L., foram utilizadas espécies bacterianas de referência, recomendadas para controle de testes de diluição: Staphylococcus aureus (ATCC 25923), Pseudomanas aeruginosa (ATCC 27853), Escherichia coli (ATCC 25922) e Salmonella enterica subsp. enterica sorovar Typhimurium (ATCC 14028).

As cepas ATCC foram semeadas em ágar Mueller-Hinton (Difco) e incubadas a $37^{\circ} \mathrm{C}$ por $24 \mathrm{~h}$ em estufa de aerobiose. A partir de cada cultivo, foi preparada uma suspensão de $1 \mathrm{~mL}$ em solução salina estéril $0,9 \%, \mathrm{pH} 7,2$, atingindo a turbidez equivalente à solução padrão 0,5 da escala de MacFarland (NCCLS, 2003).

Foram empregadas duas técnicas microbiológicas para a avaliação antibacteriana dos extratos etanólico e de ciclohexano, segundo a metodologia dos testes de sensibilidade a agentes antimicrobianos, descrita pela NCCLS (2003), com modificações.

Na técnica de diluição em caldo, foi utilizado o meio Tryptic Soy Broth (TSB - Difco), onde foram adicionados em cada tubo contendo $5 \mathrm{~mL}$ do caldo TSB, $100 \mu \mathrm{L}$ do extrato etanólico (bruto, diluído 1:1, 1:2, $1: 4,1: 8$ ou 1:10); e 100 $\mu \mathrm{L}$ da respectiva suspensão bacteriana, em triplicata. Como controle negativo foi utilizado o tubo contendo apenas o caldo TSB, e como controle positivo, o caldo TSB inoculado com $100 \mu \mathrm{L}$ da suspensão bacteriana, sem o extrato, totalizando 20 tubos por suspensão (NCCLS, 2003).

A Concentração Inibitória Mínima (CIM) foi determinada como a menor concentração do extrato que inibe o crescimento bacteriano, visível macroscopicamente, através da turvação nos tubos. Foi considerada como sensível ao extrato, a bactéria que não apresentou crescimento (turbidez) em pelo menos dois dos três tubos de caldo TSB (NCCLS, 2003).

Na técnica de difusão em ágar, $100 \mu \mathrm{L}$ de cada suspensão bacteriana foram semeadas em placas contendo ágar Mueller-Hinton (Difco), em triplicata. Com auxílio de uma pinça estéril, foram colocados sobre a superfície do meio inoculado, seis discos de papel filtro estéreis impregnados com o extrato etanólico bruto, diluído 1:1, 1:2, 1:4, 1:8 e 1:10, respectivamente. Como controle negativo foi utilizado um disco embebido em água estéril, e como controle positivo, um disco contendo álcool $70 \%$ (NCCLS, 2003).

A leitura dos resultados foi realizada medindo-se o diâmetro dos halos, em mm, formados ao redor dos discos contendo os extratos. Foi considerado como resultado final de cada extrato a média das três medidas dos halos e, como positivo, o extrato que apresentou halo maior ou igual a 9 mm, segundo Smânia et al. (1995).

Para o extrato de ciclohexano, foram realizadas as mesmas metodologias descritas acima, variando-se apenas o extrato. As placas e os tubos foram incubados em estufa de aerobiose, a $37^{\circ} \mathrm{C}$ por 24 horas.

\section{RESULTADO E DISCUSSÃO}

O extrato etanólico bruto inibiu o crescimento de Pseudomonas aeruginosa na técnica de diluição em caldo em todos os tubos (Tabela 1), em consonância com o resultado da técnica de difusão em ágar, onde se observou halo de inibição de 10 $\mathrm{mm}$ de diâmetro ao redor dos discos (Tabela 2). Com base na atividade antibacteriana apresentada pelo extrato etanólico frente a $P$. aeruginosa, o valor da Concentração Inibitória Mínima (CIM - $1 \mathrm{~g} / \mathrm{mL}$ ) é considerado alto, o que poderia justificar a inibição de crescimento bacteriano apenas no extrato bruto. Para o extrato de ciclohexano bruto e suas diluições (1:1 a 1:10), $P$. aeruginosa apresentou resistência em ambas as técnicas (Tabelas 1 e 2).

Foi observado halo de inibição nos discos contendo extrato etanólico bruto $(\mathrm{d}=8 \mathrm{~mm})$, diluído 1:1 $(\mathrm{d}=7 \mathrm{~mm})$ e diluído $1: 2(\mathrm{~d}=5 \mathrm{~mm})$ frente à Staphylococcus aureus (Tabela 2), porém, na técnica de diluição em caldo, houve crescimento desta bactéria em todas as diluições do extrato (Tabela 1), demonstrando que o mesmo não apresenta um efeito bacteriostático sobre $S$. aureus, e que o diâmetro de $8 \mathrm{~mm}$ não foi significativo. Portanto, para considerar o extrato ativo baseado em resultados equivalentes nos testes de difusão em disco e de diluição em caldo, padronizou-se o diâmetro do halo de inibição maior ou igual a $9 \mathrm{~mm}$, segundo Smânia et al. (1995). Quanto ao extrato de ciclohexano e suas diluições (1:1 a 1:10), $S$. aureus apresentou resistência em ambas as técnicas.

Não foi observada atividade antibacteriana em nenhuma concentração dos extratos etanólico e de ciclohexano frente a $E$. coli e S. enterica, tanto na técnica de difusão em ágar, como na diluição em caldo (Tabelas 1 e 2).

Resultados similares foram relatados por Fabri et al. (2011), onde o extrato metanólico da camomila apresentou atividade antibacteriana frente a $P$. aeruginosa, atividade não significativa frente a $S$. aureus, e nenhuma frente à Escherichia coli e Salmonella enterica subsp. enterica sorovar Typhimurium pelo método de susceptibilidade em microdiluição em caldo. Segundo os autores, a prospecção química do extrato identificou presença de compostos como triterpenoides, fenois, taninos e flavonoides como possíveis responsáveis pela atividade observada frente a $P$. aeruginosa. No entanto, Abdoul-Latif et al. (2011), descreveram atividade antibacteriana do extrato metanólico da 
Tabela 1. Atividade antibacteriana de extratos etanólicos e de ciclohexano obtidos de flores de camomila pela técnica de diluição em caldo frente a cepas ATCC.

\begin{tabular}{cccccc}
\hline Extrato & $\begin{array}{c}\text { Diluiçãol } \\
\text { Concentração } \\
(\mathrm{mg} / \mathrm{mL})\end{array}$ & S. aureus & P. aeruginosa & E. coli & $\begin{array}{c}\text { S. entérica } \\
\text { subsp. enterica } \\
\text { sorovar Typhimurium }\end{array}$ \\
\hline Bruto $(1000)$ & C* & AC & C & C \\
Etanólico & $1: 1(500)$ & $\mathrm{C}$ & $\mathrm{C}$ & $\mathrm{C}$ & $\mathrm{C}$ \\
& $1: 2(250)$ & $\mathrm{C}$ & $\mathrm{C}$ & $\mathrm{C}$ & $\mathrm{C}$ \\
& $1: 4(125)$ & $\mathrm{C}$ & $\mathrm{C}$ & $\mathrm{C}$ & $\mathrm{C}$ \\
& $1: 8(62,5)$ & $\mathrm{C}$ & $\mathrm{C}$ & $\mathrm{C}$ & $\mathrm{C}$ \\
& $1: 10(31,25)$ & $\mathrm{C}$ & $\mathrm{C}$ & $\mathrm{C}$ & $\mathrm{C}$ \\
& + & $\mathrm{C}$ & $\mathrm{C}$ & $\mathrm{C}$ & $\mathrm{C}$ \\
& - & $\mathrm{AC}$ & $\mathrm{AC}$ & $\mathrm{AC}$ & $\mathrm{AC}$ \\
\hline \multirow{6}{*}{ Ciclohexano } & $\mathrm{C}$ & $\mathrm{C}$ & $\mathrm{C}$ & $\mathrm{C}$ \\
& $1: 1(500)$ & $\mathrm{C}$ & $\mathrm{C}$ & $\mathrm{C}$ & $\mathrm{C}$ \\
& $1: 2(250)$ & $\mathrm{C}$ & $\mathrm{C}$ & $\mathrm{C}$ & $\mathrm{C}$ \\
& $1: 4(125)$ & $\mathrm{C}$ & $\mathrm{C}$ & $\mathrm{C}$ & $\mathrm{C}$ \\
& $1: 8(62,5)$ & $\mathrm{C}$ & $\mathrm{C}$ & $\mathrm{C}$ & $\mathrm{C}$ \\
& $1: 10(31,25)$ & $\mathrm{C}$ & $\mathrm{C}$ & $\mathrm{C}$ & $\mathrm{C}$ \\
& + & $\mathrm{C}$ & $\mathrm{C}$ & $\mathrm{C}$ & $\mathrm{C}$ \\
& - & $\mathrm{AC}$ & $\mathrm{AC}$ & $\mathrm{AC}$ & $\mathrm{AC}$ \\
\hline
\end{tabular}

${ }^{*} \mathrm{C}$ : crescimento bacteriano; AC: ausência de crescimento; (+): controle positivo; (-): controle negativo

Tabela 2. Atividade antibacteriana de extratos etanólicos e de ciclohexano obtidos de flores de camomila pela técnica de difusão em ágar frente a cepas ATCC.

\begin{tabular}{|c|c|c|c|c|c|}
\hline Extrato & $\begin{array}{l}\text { Diluição/ } \\
\text { Concentração } \\
(\mathrm{mg} / \mathrm{mL})\end{array}$ & S. aureus & P. aeruginosa & E. coli & $\begin{array}{l}\text { S. entérica } \\
\text { subsp. enterica } \\
\text { sorovar Typhimurium }\end{array}$ \\
\hline \multirow{8}{*}{ Etanólico } & Bruto (1000) & $8 \mathrm{~mm} \pm 0^{*}$ & $10 \mathrm{~mm} \pm 0$ & - & - \\
\hline & $1: 1(500)$ & $7 \mathrm{~mm} \pm 1$ & - & - & - \\
\hline & $1: 2(250)$ & $5 \mathrm{~mm} \pm 1$ & - & - & - \\
\hline & $1: 4(125)$ & - & - & - & - \\
\hline & $1: 8(62,5)$ & - & - & - & - \\
\hline & $1: 10(31,25)$ & - & - & - & - \\
\hline & Álcool 70\% & $8 \mathrm{~mm} \pm 0$ & $8 \mathrm{~mm} \pm 0$ & $8 \mathrm{~mm} \pm 0$ & $9 \mathrm{~mm} \pm 0$ \\
\hline & Água estéril & - & - & - & - \\
\hline \multirow{8}{*}{ Ciclohexano } & Bruto (1000) & - & - & - & - \\
\hline & $1: 1(500)$ & - & - & - & - \\
\hline & $1: 2(250)$ & - & - & - & - \\
\hline & $1: 4(125)$ & - & - & - & - \\
\hline & $1: 8(62,5)$ & - & - & - & - \\
\hline & $1: 10(31,25)$ & - & - & - & - \\
\hline & Álcool 70\% & $8 \mathrm{~mm} \pm 0$ & $8 \mathrm{~mm} \pm 0$ & $8 \mathrm{~mm} \pm 0$ & $9 \mathrm{~mm} \pm 0$ \\
\hline & Água estéril & - & - & - & - \\
\hline
\end{tabular}

* Média do diâmetro dos halos de inibição \pm desvio padrão (mm); (-): ausência de halo de inibição 
camomila frente à $S$. aureus, porém pela técnica de difusão em ágar (16 mm).

Asolini et al. (2006) avaliaram extratos etanólicos a partir de folhas utilizadas como chás, e o extrato de camomila não apresentou inibição contra $P$. aeruginosa e uma insignificante inibição frente a $S$. aureus $(2 \mathrm{~mm})$. Esses autores realizaram a extração a partir das folhas secas da camomila; enquanto que no presente estudo, a extração foi realizada a partir das flores secas, que apresentam princípios ativos diferentes das folhas, o que poderia justificar a diferença da atividade biológica frente a $P$. aeruginosa.

Bayoub et al. (2010) relataram que o extrato etanólico da camomila apresentou atividade antibacteriana frente a Listeria monocytogenes e $S$. aureus, porém não foi efetiva frente a $E$. coli. Silva et al. (2012) também observaram que o extrato hidroalcoólico de camomila foi eficiente contra $S$. aureus e ineficiente frente a $E$. coli.

O fato do extrato da camomila não apresentar atividade antimicrobiana frente à $S$. aureus, $E$. coli e S. enterica, não inviabiliza os estudos sobre o potencial efeito antibacteriano frente à $P$. aeruginosa, uma vez que outras espécies vegetais, comprovadamente, já apresentaram atividade antimicrobiana para esta bactéria, observando-se que há variação na sensibilidade para cada tipo de extrato vegetal utilizado. Ribeiro (2008) avaliou a atividade antimicrobiana dos extratos etanólicos brutos de diversas folhas de plantas medicinais, e constatou a formação de halo de inibição frente à $P$. aeruginosa a partir dos extratos de Psidium guajava (11 mm) e Bryophyllum calycinum (14 mm). Também houve a formação de halos variando ente 11 e $19 \mathrm{~mm}$ de diâmetro frente à $S$. aureus a partir dos extratos de Psidium guajava, Bryophyllum calycinum, Eleutherine plicata, Uncaria guianensis e Arrabidaea chica. Frente à $E$. coli, observou-se halo a partir do extrato de Arrabidaea chica $(10 \mathrm{~mm})$. Zuque et al. (2004) avaliaram extrato de Couepia grandiflora Benth. apresentando atividade antibacteriana frente à $P$. aeruginosa $(19 \mathrm{~mm})$ e $S$. aureus $(9 \mathrm{~mm})$, porém não foi eficaz para $E$. coli. Akgul \& Saglikoglu (2005) avaliaram a ação do extrato etanólico de Aniheinis tinctoria frente às bactérias $P$. aeruginosa e $S$. aureus, e observaram a formação de halo de inibição variando entre 15 a 16 mm de diâmetro.

Segundo Ribeiro (2008), não existe um consenso sobre o nível de inibição aceitável para extratos e óleos essenciais de plantas, quando comparados aos antibacterianos padrões. Porém, analisando os diâmetros dos halos do extrato etanólico bruto frente à $P$. aeruginosa $(10 \mathrm{~mm})$ com o controle positivo álcool $70 \%$ ( $8 \mathrm{~mm})$, pode ser inferida a atividade antibacteriana do extrato frente a esta bactéria.

Uma vez que a $P$. aeruginosa é considerada um patógeno de grande importância em saúde pública e animal, e que vem desenvolvendo crescente resistência aos antimicrobianos, sendo, portanto, de difícil controle, os resultados do presente estudo denotam a importância da atividade antibacteriana do extrato da camomila frente a esta bactéria, já que diversos estudos relataram a resistência da mesma a diferentes extratos vegetais (Santos et al., 2011; Pelissari et al., 2010; Cordeiro et al., 2006; Andrade et al., 2005; Vasconcelos et al., 2004; Lima-Filho et al., 2002). Tal fato reforça a hipótese de que o extrato da camomila pode ter potencial para fornecer substâncias com atividade antibacteriana in vitro.

De acordo com os resultados apresentados, o extrato bruto de ciclohexano e as suas diluições, em ambas as técnicas microbiológicas, não apresentaram atividade antibacteriana, enquanto que no extrato etanólico bruto observou-se inibição. A utilização de diferentes solventes na preparação dos extratos, um polar (etanol) e outro apolar (ciclohexano), pode ter interferido na sua atividade biológica. Segundo Nascimento et al. (2006) e Bayoub et al. (2010), o extrato etanólico apresenta capacidade maior de inibir o crescimento bacteriano, pois consegue uma melhor extração dos princípios ativos polares das plantas, os quais refletem nessa ação antibacteriana. Tal fato pode ser corroborado pelo estudo de Romero et al. (2005), onde não foi observada inibição de $S$. aureus, $E$. coli e $P$. aeruginosa a partir do extrato aquoso da camomila. Segundo os autores, muitos dos compostos antimicrobianos já identificados em plantas são aromáticos ou saturados de moléculas orgânicas, tornando o etanol um solvente ideal. Isto pode ser o resultado da falta de solubilidade dos componentes ativos em soluções apolares.

Devido à escassez de estudos que indiquem as possíveis moléculas ativas a partir de extratos da camomila, os resultados apresentados reforçam a necessidade de novas pesquisas com este extrato frente a outras estirpes de $P$. aeruginosa e de outros microrganismos, com o intuito de corroborar e assegurar os resultados apresentados, para definir o potencial antimicrobiano da camomila, visto que o extrato etanólico bruto apresentou atividade biológica positiva frente a esta bactéria, justificando a presença de componentes ativos.

Tais resultados reforçam a hipótese de que o extrato da camomila pode ter potencial atividade antibacteriana in vitro frente à $P$. aeruginosa, e este estudo denota a importância dos dados de levantamentos etnofarmacológicos na seleção de plantas que podem ser utilizadas na medicina tradicional.

\section{REFERÊNCIA}

ABDOUL-LATIF, F.M. et al. Antimicrobial and antioxidant activities of essential oil and methanol extract of 
Matricaria chamomilla L. from Djibouti. Journal of Medicinal Plants Research. v.5, n.9, p.1512-1517, 2011.

AKGUL, C.; SAGLIKOGLU, G. Antibacterial activity of crude methanolic extract and its fractions of aerial parts of Anthemis tinctoria. Indian Journal Biochemistry Biophysics, v.42, n.6, p.395-397, 2005.

ANDRADE, C.A. et al. Avaliação da atividade antibacteriana e triagem fitoquímica das flores de Acacia podalyriifolia A. Cunn. ex G. Don Leguminosae-Mimosoideae. Revista Brasileira de Farmacognosia, v.15, n.1, p.13-15, 2005.

ASOLINI, F.C. et al. Atividade antioxidante e antibacteriana dos compostos fenólicos dos extratos de plantas usadas como chás. Brazilian Journal of Food Technology, v.9, n.3, p. 209-215, 2006.

BAYOUB, K. et al. Antibacterial activities of the crude ethanol extracts of medicinal plants against Listeria monocytogenes and some other pathogenic strains. African Journal of Biotechnology, v.9, n.27, p.42514258, 2010.

BRASIL. Farmacopéia Brasileira. $5^{\mathrm{a}}$ edição. Brasília: Agência Nacional de Vigilância Sanitária. 2010. 546p. Disponível em: <http://www.anvisa.gov.br/hotsite/ cd_farmacopeia/index.htm>. Acesso em: 11 jun. 2012.

CORDEIRO, C.H.G. et al. Análise farmacognóstica e atividade antibacteriana de extratos vegetais empregados em formulação para a higiene bucal. Brazilian Journal of Pharmaceutical Sciences, v. 42, n. 3, p.395-404, 2006.

DUARTE, M.C.T. Atividade antimicrobiana de plantas medicinais e aromáticas utilizadas no Brasil. Revista Multiciência, n.7, 2006. Disponível em: <http://www. multiciencia.unicamp.br/ artigos_07/a_05_7.pdf>. Acesso em: 13 nov. 2011.

FABRI, R.L. et al. Potencial antioxidante e antimicrobiano de espécies da família asteraceae. Revista Brasileira de Plantas Medicinais, v.13, n.2, p. 183-189, 2011.

LIMA-FILHO, J.V.M. et al. Antibacterial activity of extracts of six Macroalgae from the Northeastern Brazilian coast. Brazilian Journal of Microbiology, v.33, p.311-313, 2002.

LORENZI, H.; MATOS, F.J. A. Plantas medicinais no Brasil - nativas e exóticas. Edição 2. São Paulo: Instituto Plantarum de Estudos da Flora, 2002. 512p.

NASCIMENTO, G.G.F. et al. Antibacterial activity of plant extracts and phytochemicals on antibiotic-resistant bacteria. Brazilian Journal of Microbiology, v.31, n.4, p.247-56, 2000.

NASCIMENTO, L.C.S. et al. Atividade antimicrobiana in vitro de extratos vegetais de Solanum paniculatum
L. sobre o crescimento de Ralstonia solanacearum. In: CONGRESSO BRASILEIRO DE QUÍMICA, n.46, 2006, Salvador. Anais eletrônicos... Salvador: CESI/ UEMA, 2006. Disponível em: <http://www.abq.org.br/ cbq/2006/trabalhos

2006/13/36-IC-505-690-13-T1.htm>. Acesso em: 09 jul. 2012.

NCCLS. Methods for Dilution Antimicrobial Susceptibility Tests for Bacteria That Grow Aerobically; Approved Standard. Sixth Edition. NCCLS document M7-A6 (ISBN 1-56238 486-4), v.23, n.2, 2003. Disponível em: <http:// www.sbac.org.br/pt/pdfs/biblioteca/clsi_OPASM7_A6.pdf>. Acesso em: 04 out. 2011.

PELISSARI, G.P. et al. Atividade antibacteriana do óleo essencial de Melampodium divaricatum (Rich.) DC., Asteraceae. Revista Brasileira de Farmacognosia, v.20, n.1, p.70-74, 2010.

RIBEIRO, C. M. Avaliação da atividade antimicrobiana de plantas utilizadas na medicina popular da Amazônia. 2008. 67p. Dissertação (Mestrado em Ciências Farmacêuticas) Universidade Federal do Pará, Belém.

ROMERO, C.D. et al. Antibacterial properties of common herbal remedies of the southwest. Journal of Ethnopharmacology, v.99, p.253-257, 2005.

SANTOS, S. C. et al. Atividade antimicrobiana in vitro do extrato de Abarema cochliocarpos (Gomes) Barnaby \& Grimes. Revista Brasileira de Farmacognosia, v.17, n.2, p.215-219, 2007.

SANTOS, V.L. et al. Avaliação da atividade antimicrobiana de Maytenus rigida Mart. (Celastraceae). Revista Brasileira de Plantas Medicinais, v.13, n.1, p.68-72, 2011.

SILVA, N.C.C. et al. Antimicrobial activity and phytochemical analysis of crude extracts and essential oils from medicinal plants. Natural Product Research, v.26, n.16, p. 1510-1514, 2012.

SMÂNIA, A. et al. Antibacterial activity of a substance produced by the fungus Pycnoporus sanguineus (Fr.) Murr. Journal of Ethnopharmacology, v.45, p.177181, 1995.

VASCONCELOS, M.C.A. et al. Avaliação de atividades biológicas das sementes de Stryphnodendron obovatum Benth. (Leguminosae). Revista Brasileira de Farmacognosia, v.14, n.1, p.121-127, 2004.

YUNES, R.A.; CALIXTO, J.B. Plantas medicinais, sob a ótica da química medicinal moderna. Edição 1. Chapecó: Argos. 2001. 523p.

ZUQUE, A.L.F. Avaliação das atividades antioxidante, antimicrobiana e citotóxica de Couepia grandiflora Benth. (Chrysobalanaceae). Revista Brasileira de Farmacognosia, v.14, n.2, p.126-136, 2004. 